\title{
CONTROLE PÓS-COLHEITA DA ANTRACNOSE DA BANANA -PRATA ANÃ TRATADA COM FUNGICIDAS E MANTIDA SOB REFRIGERAÇÃO
}

\author{
Dwarf silver banana post-harvest anthracnose control with fungicides and under refrigeration
}

\author{
Ana Flávia Santos Coelho', Mário Sérgio de Carvalho Dias², Maria Luisa Mendes Rodrigues², \\ Paulo Ademar Martins Leal ${ }^{3}$
}

\begin{abstract}
RESUMO
A antracnose é uma das principais doenças após a colheita da banana, causada pelas diferentes raças fisiológicas do fungo Colletotrichum musae, e que se manifesta na maioria das vezes na fruta madura, comprometendo a sua qualidade. Seu aparecimento está relacionado ao manuseio inadequado, ausência de controle químico em campo e de refrigeração. A aplicação de produtos químicos é efetuada durante o beneficiamento, sendo importante salientar que pode iniciar com a fruta ainda no campo. Objetivou-se, neste trabalho, verificar o efeito de fungicidas utilizados após a colheita, visando o controle da antracnose em bananas, cultivar Prata Anã, armazenadas a $20^{\circ} \mathrm{C} \mathrm{e} 12^{\circ} \mathrm{C}$. Para isso, foi testada a ação dos fungicidas tiabendazol e imazalil no controle de Colletotrichum musae. No teste, foram empregados isolados das cultivares Prata Anã, FHIA 02 e ST 4208, inoculados em bananas-prata anã. As avaliações foram efetuadas a cada 3 dias, por meio de medições do tamanho das lesões $\left(\mathrm{mm}^{2}\right)$, sendo as frutas inoculadas descartadas no estádio de maturação 7 (amarelo com pontas marrom). Os tratamentos mais eficientes no controle da doença foram aqueles em que as bananas foram tratadas com o fungicida tiabendazol. No estudo, também foi verificada diferença em relação à patogenicidade dos isolados utilizados, que demonstraram especificidade quanto a cultivar.
\end{abstract}

Termos para indexação: Musa sp. , doenças pós-colheita, antracnose, controle químico.

\begin{abstract}
Anthracnose is one of the main post-harvest disease of the banana, caused by different physiological races of Colletotrichum musae. It manifests itself mostly in ripe fruits, threatening its quality. Its appearance is related to the inadequate handling, absence of chemical control in field, and cooling. Application of chemical products is usually done during the processing, but it is important to point out that it can be done while the fruit is still in the field. This work had as an objective to verify the effect post-harvest application of fungicides to control anthracnose in Dwarf Silver bananas, stored at $20^{\circ} \mathrm{C}$ and $12^{\circ} \mathrm{C}$. To that end, the influence of the thiabendazole and imazalil fungicides was tested on Colletotrichum musae. In the tests we employed Dwarfed Silver isolates of cultivars FHIA 02 and ST 4208 inoculated in Dwarfed Silver bananas. The evaluations were done every 3 days, by measuring the size of injuries $\left(\mathrm{mm}^{2}\right)$. The inoculated fruits were discarded in the stage 7 of maturation (yellow with brown tips). The most efficient treatments in disease control were those in which the bananas were treated with the thiabendazole fungicide. The difference in relation to the pathogenicity of the isolates used, demonstrated the specificity of the cultivar.
\end{abstract}

Index terms: Musa sp., post-harvest disease, anthracnose, chemical control.

(Recebido em 19 de junho de 2008 e aprovado em 5 de agosto de 2009)

\section{INTRODUÇÃO}

A incidência de patógenos causadores de doenças após a colheita é um dos problemas que prejudica a qualidade e que tem limitado a exportação de frutas brasileiras. No caso da banana, várias podridões podem ocorrer nessa fase, porém o maior destaque é dado à antracnose, causada pelo fungo Colletotrichum musae, que se manifesta, principalmente, na fruta madura (Ventura \& Hinz, 2002). É importante destacar que, dentro dessa espécie, há a existência de tipos biológicos ou raças fisiológicas (Couto \& Menezes, 2004).
A doença é caracterizada pela formação de lesões deprimidas, escuras, com o eixo maior paralelo ao eixo longitudinal e delimitada por uma margem mais clara nos tecidos sadios. Sob condições de alta umidade, cobrem-se de frutificação rosada, ou acérvulos do agente patogênico. Geralmente, as lesões são superficiais, mas podem, em casos severos, com o amadurecimento da fruta, atingir a polpa (Kimati et al., 2005).

A importância da antracnose está ligada à frequência com que aparece, principalmente, nas condições de comércio interno em que, poucos cuidados são tomados do ponto de vista de manuseio, ausência de controle químico em campo e

\footnotetext{
1'Universidade Federal do Tocantins/ UFT - Laboratório de Microbiologia de Alimentos - Avenida NS15 - ALCNO14 - 77020-210 - anaflavia@uft.edu.br 2EPAMIG - Nova Porteirinha, MG

3Universidade Estadual de Campinas/UNICAMP - Faculdade de Engenharia Agrícola/FEAGRI - Distrito de Barão Geraldo - Campinas, SP
} 
de refrigeração. Para o controle do C. musae, devem-se considerar aspectos relacionados ao manejo adequado na pré-colheita, colheita e após a colheita, já que a cultivar Prata Anã é susceptível à doença (Ventura \& Hinz, 2002).

Apesar de estudos demonstrarem a eficiência no controle da antracnose por meio de métodos alternativos à utilização de fungicidas (Lima et al., 2007; Nolasco et al., 2008), este ainda é o mais comum.

Levando-se em consideração os fungicidas registrados para o controle da antracnose na banana e a existência de raças fisiológicas do patógeno causador da doença, objetivou-se, neste trabalho, verificar a ação de dois fungicidas (tiabendazol e imazalil) no controle de $C$. musae isolado de três cultivares de bananas (Prata Anã, FHIA 02 e ST 4208), que foram inoculados em bananas Prata Anã, armazenadas a $20^{\circ} \mathrm{C}$ e $12^{\circ} \mathrm{C}$.

\section{MATERIAL E MÉTODOS}

Para as inoculações, foram utilizados isolados de C. musae obtidos de lesões de bananas (Prata Anã, FHIA 02 e ST 4208), com sintomas característicos de antracnose, provenientes da Fazenda Experimental do Gorutuba. Os isolamentos do patógeno da casca da banana foram efetuados de acordo com Tuite (1969). As colônias típicas de $C$. musae desenvolvidas no meio de cultura, depois de identificadas ao microscópio ótico, foram padronizadas por meio de cultivo monospórico.

Para avaliação da eficiência do tratamento químico, foram utilizadas bananas Prata Anã, colhidas na Fazenda Experimental do Gorutuba, no estádio de maturação 1 (verde). No preparo das frutas utilizadas no experimento, as pencas foram separadas em dedos e estes foram lavados com detergente e água corrente. Depois de totalmente secos, os dedos passaram por uma etapa de desinfestação, quando foi borrifado hipoclorito de sódio (1,5\%) e após 15 minutos foram lavados com água destilada esterilizada e secos naturalmente.

A inoculação consistiu na abertura de um orifício, no centro dos dedos, de aproximadamente $3 \mathrm{~mm}$ de diâmetro e $3 \mathrm{~mm}$ de profundidade no epicarpo da fruta, feito com auxílio de um vazador e escalpelo, onde foi inserido um disco de mesmo diâmetro retirado da borda da colônia do patógeno desenvolvida em meio de BDA + antibiótico.

Os dedos foram tratados com: tiabendazol $(41 \mathrm{~mL} /$ $100 \mathrm{~L}$ de água, tempo de ação três minutos) e imazalil (200 $\mathrm{mL} / 100 \mathrm{~L}$ de água, tempo de ação dois minutos), 5 horas após a inoculação.

Após os tratamentos, os dedos foram colocados em bandejas plásticas, previamente esterilizadas, para retirada do excesso dos fungicidas e secagem, sendo posteriormente transferidos para outras bandejas forradas com papel de filtro, contendo um chumaço de algodão umedecido com água esterilizada, e recobertas com filme plástico. Essas bandejas foram mantidas em câmaras de refrigeração a $12^{\circ}$ e $20^{\circ} \mathrm{C}$ e umidade relativa a $95 \%$. O controle da temperatura e da umidade relativa foi efetuado por meio do painel de controle da câmara fria, sendo realizado o monitoramento por meio de dois termohigrômetros digitais situados em cantos opostos de cada uma das câmaras.

As avaliações foram efetuadas a cada três dias por meio da determinação do tamanho das lesões $\left(\mathrm{mm}^{2}\right)$, sendo utilizada a seguinte fórmula:

$$
\mathrm{TL}=(\mathrm{C} \times \mathrm{L}) / 2
$$

Em que:

$\mathrm{TL}=$ tamanho da lesão $\left(\mathrm{mm}^{2}\right)$

$\mathrm{C}=$ comprimento da lesão $(\mathrm{mm})$

$\mathrm{L}=$ largura da lesão $(\mathrm{mm})$

As medições foram efetuadas com auxílio de um paquímetro analógico e as frutas foram descartadas no estádio de maturação 7 (amarelo com pontas marrom).

Após cada avaliação, o chumaço de algodão contido nas bandejas foi umedecido com água destilada esterilizada, de modo a fornecer umidade adequada para o desenvolvimento do patógeno.

O descarte das frutas foi efetuado após seis dias de armazenamento, quando as bananas atingiram o estádio de maturação 7 .

\section{Análise estatística}

$\mathrm{O}$ delineamento experimental utilizado foi o inteiramente casualizado (DIC), em esquema fatorial $4 \times 3 \times 2$, sendo os fatores representados por 3 isolados de $C$. musae e o controle; 2 fungicidas aplicados após a colheita e o controle e 2 temperaturas de armazenamento, perfazendo um total de 24 tratamentos. Cada parcela consistiu de cinco frutas, foram efetuadas quatro repetições, totalizando 20 frutas por tratamento.

Tratamentos testados:

\begin{tabular}{cl}
\hline \multirow{2}{*}{$\begin{array}{c}\text { Compostos químicos } \\
\text { aplicados após a colheita }\end{array}$} & $\begin{array}{c}\mathrm{S} \text { de composto químico) } \\
\mathrm{T}=\text { tiabendazole } \\
\mathrm{I}=\text { imazalil }\end{array}$ \\
\hline \multirow{2}{*}{ Temperaturas } & $\mathrm{A}=20^{\circ} \mathrm{C}$ \\
& $\mathrm{B}=12^{\circ} \mathrm{C}$ \\
\hline \multirow{2}{*}{ Isolados } & $\mathrm{C}=$ controle (sem isolado) \\
& $\mathrm{P}=\mathrm{C}$. musae Prata Anã \\
& $\mathrm{F}=\mathrm{C}$. musae FHIA 02 \\
& $\mathrm{S}=\mathrm{C}$. musae ST 4208 \\
\hline
\end{tabular}


Para o tratamento testemunha, foram utilizadas frutas em que se seguiu a mesma metodologia, utilizando, no entanto, discos de BDA + antibiótico sem o patógeno.

Os dados foram submetidos à análise de variância e teste de Tukey, a 5\% de significância, para comparação das médias.

\section{RESULTADOS E DISCUSSÃO}

O tamanho da lesão, ao longo do tempo, nas bananas armazenadas na temperatura de $20^{\circ} \mathrm{C}$ pode ser visualizado na Tabela 1 . De maneira geral, observa-se um aumento do tamanho da lesão, com o passar do tempo de armazenamento.

Os tratamentos mais eficientes foram aqueles em que as bananas foram tratadas com tiabendazole, pois a lesão das frutas previamente inoculadas com $C$. musae isolado das cultivares banana Prata Anã, FHIA 02 e ST 4208 (TAP, TAF e TAS) só começou a se desenvolver no último dia de armazenamento. Como esperado, nos tratamentos onde não foi efetuada a inoculação não houve o desenvolvimento da lesão. Esse comportamento foi observado nas bananas não inoculadas com o patógeno e tratadas com o fungicida imazalil (IAC) e nas bananas que receberam um disco de ágar batata dextrose sem o inóculo, mas não foram submetidas ao tratamento com os fungicidas testados (SAC). Como observado na Tabela 1, os tratamentos TAP, TAF e TAS não diferem entre si estatisticamente, ao nível de 5\% de significância. Nos demais tratamentos, em que todas as frutas foram inoculadas com o patógeno, sendo posteriormente tratadas com o fungicida imazalil (IAP, IAF e IAS) e nas bananas não tratadas com fungicida (SAP, SAF e SAS), foi verificado um aumento do tamanho da lesão, ao longo dos dias de armazenamento. Nesse caso, verifica-se que o fungicida imazalil apresentou menor efeito no controle do C. musae, quando comparado ao fungicida tiabendazol.

Os valores obtidos permitem também observar uma diferença em relação ao desenvolvimento das lesões. $\mathrm{O}$ tamanho da lesão provocada por $C$. musae isolado da cultivar Prata Anã e inoculado em bananas da mesma cultivar difere, estatisticamente, do tamanho da lesão provocada pelos demais isolados, quando não foram utilizados fungicidas. No tratamento em que as frutas não sofreram aplicação de produto químico, mas foram inoculadas com C. musae de banana Prata Anã (SAP), o tamanho médio da lesão foi de $404,42 \mathrm{~mm}^{2}$ e nos outros onde as bananas foram inoculadas com isolados da cultivar FHIA 02 e ST 4208 (SAF e SAS), o tamanho médio de lesão foi igual a $267,85 \mathrm{~mm}^{2}$ e $205,85 \mathrm{~mm}^{2}$, respectivamente, sugerindo que esses últimos foram menos agressivos.
Tabela 1 - Valores médios do tamanho da lesão $\left(\mathrm{mm}^{2}\right)$ provocada pela inoculação de $C$. musae em bananas Prata Anã, tratadas com produtos químicos e armazenada à temperatura de $20^{\circ} \mathrm{C}$.

\begin{tabular}{lccc}
\hline \multirow{2}{*}{ Tratamento } & \multicolumn{3}{c}{ Dia } \\
\cline { 2 - 4 } & \multicolumn{1}{c}{0} & 6 \\
\hline TAC & $0,00^{\mathrm{A}, \mathrm{a}}$ & $0,00^{\mathrm{A}, \mathrm{a}}$ & $0,00^{\mathrm{A}, \mathrm{a}}$ \\
TAP & $0,00^{\mathrm{A}, \mathrm{a}}$ & $0,00^{\mathrm{A}, \mathrm{a}}$ & $4,50^{\mathrm{A}, \mathrm{a}}$ \\
TAF & $0,00^{\mathrm{A}, \mathrm{a}}$ & $0,00^{\mathrm{A}, \mathrm{a}}$ & $2,30^{\mathrm{A}, \mathrm{a}}$ \\
TAS & $0,00^{\mathrm{A}, \mathrm{a}}$ & $0,00^{\mathrm{A}, \mathrm{a}}$ & $1,26^{\mathrm{A}, \mathrm{a}}$ \\
IAC & $0,00^{\mathrm{A}, \mathrm{a}}$ & $0,00^{\mathrm{A}, \mathrm{a}}$ & $0,00^{\mathrm{A}, \mathrm{a}}$ \\
IAP & $0,00^{\mathrm{A}, \mathrm{a}}$ & $80,60^{\mathrm{A}, \mathrm{B}, \mathrm{a}}$ & $332,29^{\mathrm{C}, \mathrm{D}, \mathrm{b}}$ \\
IAF & $0,00^{\mathrm{A}, \mathrm{a}}$ & $149,69^{\mathrm{A}, \mathrm{B}, \mathrm{b}}$ & $279,73^{\mathrm{C}, \mathrm{D}, \mathrm{c}}$ \\
IAS & $0,00^{\mathrm{A}, \mathrm{a}}$ & $19,62^{\mathrm{A}, \mathrm{a}}$ & $47,87^{\mathrm{A}, \mathrm{B}, \mathrm{a}}$ \\
SAC & $0,00^{\mathrm{A}, \mathrm{a}}$ & $0,00^{\mathrm{A}, \mathrm{a}}$ & $0,00^{\mathrm{A}, \mathrm{a}}$ \\
SAP & $0,00^{\mathrm{A}, \mathrm{a}}$ & $236,10^{\mathrm{B}, \mathrm{b}}$ & $404,42^{\mathrm{D}, \mathrm{c}}$ \\
SAF & $0,00^{\mathrm{A}, \mathrm{a}}$ & $105,52^{\mathrm{A}, \mathrm{B}, \mathrm{a}}$ & $267,85^{\mathrm{C}, \mathrm{b}}$ \\
SAS & $0,00^{\mathrm{A}, \mathrm{a}}$ & $95,08^{\mathrm{A}, \mathrm{B}, \mathrm{a}, \mathrm{b}}$ & $205,85^{\mathrm{B}, \mathrm{C}, \mathrm{b}}$ \\
\hline
\end{tabular}

Valores médios com mesma letra maiúscula na coluna e mesma letra minúscula na linha, não diferem significativamente (teste de Tukey, $5 \%$ de probabilidade).

As frutas inoculadas com C. musae e tratadas com tiabendazol apresentaram as menores lesões. Mesmo com o aparecimento da doença, no último dia de armazenamento, a lesão causada foi significativamente menor do que nas bananas inoculadas com o patógeno e tratadas com o fungicida imazalil ou que não sofreram tratamento com fungicida. Ambas não diferiram significativamente.

A Tabela 2 apresenta o comportamento do tamanho da lesão provocada pela inoculação de $C$. musae, nas bananas armazenadas a $12^{\circ} \mathrm{C}$. $\mathrm{O}$ armazenamento na temperatura mais baixa foi um fator importante no retardo do desenvolvimento da lesão, permitindo o acompanhamento das frutas, durante um período de 15 dias. Na Tabela 2, verifica-se que as lesões, para a maioria dos tratamentos, só surgiram aos seis dias de armazenamento das frutas. Lima et al. (2001) testaram o armazenamento de banana Prata Anã sob refrigeração a $12^{\circ} \mathrm{C}$ e $97 \%$ de umidade relativa e verificaram o ataque do patógeno, após 10 dias de armazenamento das frutas.

Novamente, constatou-se, como ocorrido nas frutas armazenadas a $20^{\circ} \mathrm{C}$, que os tratamentos em que as bananas foram previamente inoculadas com os isolados e tratadas com tiabendazole (TBC, TBP, TBF) foram os mais eficientes, não diferindo entre si ao longo dos dias de armazenamento. 
Tabela 2 - Valores médios do tamanho da lesão $\left(\mathrm{mm}^{2}\right)$ provocada pela inoculação de $C$. musae em bananas Prata Anã tratadas com produtos químicos e armazenadas à temperatura de $12^{\circ} \mathrm{C}$.

\begin{tabular}{lcccccc}
\hline \multirow{2}{*}{ Tratamento } & \multicolumn{5}{c}{ Dia } \\
\cline { 2 - 6 } & 0 & 3 & 6 & 9 & 12 & $15^{\mathrm{A}}$ \\
\hline TBC & $0,00^{\mathrm{A}, \mathrm{a}}$ & $0,00^{\mathrm{A}, \mathrm{a}}$ & $0,00^{\mathrm{A}, \mathrm{a}}$ & $0,00^{\mathrm{A}, \mathrm{a}}$ & $0,00^{\mathrm{A}, \mathrm{a}}$ & $0,00^{\mathrm{A}, \mathrm{a}}$ \\
TBP & $0,00^{\mathrm{A}, \mathrm{a}}$ & $0,00^{\mathrm{A}, \mathrm{a}}$ & $0,00^{\mathrm{A}, \mathrm{a}}$ & $0,00^{\mathrm{A}, \mathrm{a}}$ & $3,00^{\mathrm{A}, \mathrm{a}}$ & $6,56^{\mathrm{A}, \mathrm{a}}$ \\
TBF & $0,00^{\mathrm{A}, \mathrm{a}}$ & $0,00^{\mathrm{A}, \mathrm{a}}$ & $0,00^{\mathrm{A}, \mathrm{a}}$ & $0,00^{\mathrm{A}, \mathrm{a}}$ & $0,00^{\mathrm{A}, \mathrm{a}}$ & $13,96^{\mathrm{A}, \mathrm{a}}$ \\
TBS & $0,00^{\mathrm{A}, \mathrm{a}}$ & $0,00^{\mathrm{A}, \mathrm{a}}$ & $0,00^{\mathrm{A}, \mathrm{a}}$ & $0,00^{\mathrm{A}, \mathrm{a}}$ & $0,00^{\mathrm{A}, \mathrm{a}}$ & $0,00^{\mathrm{A}, \mathrm{a}}$ \\
IBC & $0,00^{\mathrm{A}, \mathrm{a}}$ & $0,00^{\mathrm{A}, \mathrm{a}}$ & $0,00^{\mathrm{A}, \mathrm{a}}$ & $0,00^{\mathrm{A}, \mathrm{a}}$ & $0,00^{\mathrm{A}, \mathrm{a}}$ & $0,00^{\mathrm{A}, \mathrm{a}}$ \\
IBP & $0,00^{\mathrm{A}, \mathrm{a}}$ & $0,00^{\mathrm{A}, \mathrm{a}}$ & $0,00^{\mathrm{A}, \mathrm{a}}$ & $0,00^{\mathrm{A}, \mathrm{a}}$ & $108,24^{\mathrm{B}, \mathrm{C}, \mathrm{b}}$ & $510,73^{\mathrm{D}, \mathrm{c}}$ \\
IBF & $0,00^{\mathrm{A}, \mathrm{a}}$ & $0,00^{\mathrm{A}, \mathrm{a}}$ & $16,04^{\mathrm{A}, \mathrm{a}}$ & $70,36^{\mathrm{A}, \mathrm{a}, \mathrm{b}}$ & $142,42^{\mathrm{C}, \mathrm{b}}$ & $344,26^{\mathrm{C}, \mathrm{c}}$ \\
IBS & $0,00^{\mathrm{A}, \mathrm{a}}$ & $0,00^{\mathrm{A}, \mathrm{a}}$ & $0,00^{\mathrm{A}, \mathrm{a}}$ & $0,00^{\mathrm{A}, \mathrm{a}}$ & $5,47^{\mathrm{A}, \mathrm{a}}$ & $50,51^{\mathrm{A}, \mathrm{a}}$ \\
SBC & $0,00^{\mathrm{A}, \mathrm{a}}$ & $0,00^{\mathrm{A}, \mathrm{a}}$ & $0,00^{\mathrm{A}, \mathrm{a}}$ & $0,00^{\mathrm{A}, \mathrm{a}}$ & $0,55^{\mathrm{A}, \mathrm{a}}$ & $0,82^{\mathrm{A}, \mathrm{a}}$ \\
SBP & $0,00^{\mathrm{A}, \mathrm{a}}$ & $0,00^{\mathrm{A}, \mathrm{a}}$ & $0,00^{\mathrm{A}, \mathrm{a}}$ & $18,59^{\mathrm{A}, \mathrm{a}}$ & $38,43^{\mathrm{A}, \mathrm{B}, \mathrm{a}}$ & $382,25^{\mathrm{C}, \mathrm{b}}$ \\
SBF & $0,00^{\mathrm{A}, \mathrm{a}}$ & $0,00^{\mathrm{A}, \mathrm{a}}$ & $10,44^{\mathrm{A}, \mathrm{a}, \mathrm{b}}$ & $37,18^{\mathrm{A}, \mathrm{a}, \mathrm{b}}$ & $92,60^{\mathrm{A}, \mathrm{B}, \mathrm{C}, \mathrm{b}, \mathrm{c}}$ & $155,54^{\mathrm{B}, \mathrm{c}}$ \\
SBS & $0,00^{\mathrm{A}, \mathrm{a}}$ & $0,00^{\mathrm{A}, \mathrm{a}}$ & $0,00^{\mathrm{A}, \mathrm{a}}$ & $0,00^{\mathrm{A}, \mathrm{a}}$ & $0,00^{\mathrm{A}, \mathrm{a}}$ & $89,91^{\mathrm{A}, \mathrm{B}, \mathrm{b}}$ \\
\hline
\end{tabular}

Valores médios com mesma letra maiúscula na coluna e mesma letra minúscula na linha, não diferem significativamente (teste de Tukey, $5 \%$ de probabilidade).

Em alguns dos demais tratamentos, a lesão começou a surgir a partir do sexto dia de armazenamento, mesmo nas frutas tratadas com o fungicida imazalil. Nesses tratamentos, também foi verificado maior desenvolvimento das lesões em frutas inoculadas com C. musae, isolado de bananas da mesma cultivar. No décimo quinto dia de armazenamento, as bananas tratadas com imazalil (IBP) apresentaram tamanho médio da lesão de $510,73 \mathrm{~mm}^{2} \mathrm{e}$ as bananas que não receberam aplicação de produto químico (SBP) apresentaram tamanho médio da lesão de $382,25 \mathrm{~mm}^{2}$.

Apesar de constatada a existência de raças de $C$. musae que são resistentes ao tiabendazol, Chillet et al. (2000) sugerem que o aparecimento da doença não deve ser explicado apenas por essa razão, mas também pela qualidade da banana, muito influenciada por fatores edafoclimáticos. De acordo com pesquisa realizada pelos autores, pode haver uma relação entre o status mineral da planta e a susceptibilidade da fruta à doença.

Trabalhos apontam para a importância de testes de patogenicidade em inoculações cruzadas em diversos hospedeiros como forma de caracterização patogência entre isolados. Tais trabalhos visam demonstrar a especificidade ou a gama de hospedeiros isolados ou espécies distintas. Peres et al. (2002), ao avaliar a ação de espécies de Colletotrichum isoladas de diferentes frutas e inoculadas em bananas, verificou que sete dias após a inoculação, $100 \%$ das frutas apresentaram incidência de C. musae, com lesões de diâmetro médio de 12,65 mm. As frutas inoculadas com C. acutatum e Colletotrichum spp. não apresentaram sintomas da doença tão agressivos quanto comparadas àquelas inoculadas com isolados do hospedeiro de origem. Tais resultados comprovam a especificidade e a importância do C. musae como agente causal da antracnose, em frutas de bananeira. Resultado que comprova também essa especificidade foi encontrado por Lima Filho et al. (2003). No estudo, os autores demonstraram a suscetibilidade das frutas de maracujazeiro somente quando inoculados com o patógeno isolado do hospedeiro. As bananas apresentaram-se susceptíveis a isolados de Colletotrichum de outras frutas (caju, manga, mamão e maracujá), porém a maior lesão foi provocada pelo isolado da banana.

\section{CONCLUSÕES}

Os tratamentos mais eficientes no controle da doença foram aqueles em que as frutas foram tratadas com o fungicida tiabendazol, tanto nas frutas armazenadas a $20^{\circ} \mathrm{C}$ quanto a $12^{\circ} \mathrm{C}$;

C. musae isolado de banana Prata Anã é mais agressivo que isolados do mesmo fungo obtidos de outras cultivares se inoculados na cultivar Prata Anã;

$\mathrm{O}$ armazenamento a $12^{\circ} \mathrm{C}$ foi um fator importante no retardo do desenvolvimento das lesões;

O tratamento com o fungicida imazalil, nas condições testadas, demonstrou pouco efeito no controle do patógeno causador da antracnose, em bananas previamente inoculadas. 


\section{REFERÊNCIAS BIBLIOGRÁFICAS}

CHILLET, M.; BELLAIRE, L.L. de; DOREL, M.; JOAS, J.; DUBOIS, C.; MARCHAL, J.; PERRIER, X. Evidence for the variation in susceptibility of bananas to wound anthracnose due to Colletotrichum musae and the influence of edaphic conditions. Scientia Horticulturae, Amsterdam, v.86, p.33-47, 2000.

COUTO, E.F.; MENEZES, M. Caracterização fisiomorfológica de isolados de C. musae. Fitopatologia Brasileira, Brasília, v.29, p.406-412, 2004.

KIMATI, H.; AMORIM, L.; REZENDE, J.A.M.; BERGAMIM FILHO, A.; CAMARGO, L.E.A. Manual de fitopatologia: doenças das plantas cultivadas. São Paulo: Ceres, 2005. v.2, 663p.

LIMA, L.C.; CASTRO, M.V. de; DIAS, M.S. de C.; MARTINS, R.M.; SILVA, D.F.; COSTA, S.; RIBEIRO JUNIOR, P.M.; BRESINSKI, T.L. Conservação póscolheita de banana Prata Anã produzida na região de Minas Gerais. In: SIMPÓSIO NORTE MINEIRO SOBRE A CULTURA DA BANANA, 1., 2001, Nova Porteirinha. Anais... Nova Porteirinha: Epamig, 2001. p.272-274.

LIMA, L. C.; DIAS, M. S. C.; CASTRO, M. V. de; RIBEIRO JÚNIOR, P. M.; SILVA, E. de B. Controle da antracnose e qualidade de mangas (Mangifera indica L.) cv. haden, após tratamento hidrotémico e armazenamento refrigerado em atmosfera modificada. Ciência e Agrotecnologia, v.31, n.2, p. 298-304, mar./ abr., 2007.

LIMA FILHO, R.M.; OLIVEIRA, S.M.A.; MENEZES, M. Caracterização enzimática e patogenicidade cruzada de Colletotrichum spp. associados a doenças de póscolheita. Fitopatologia Brasileira, Brasília, n.28, p.620625, nov./dez. 2003.

NOLASCO, C. de A.; SALOMÃO, L. C. C.; CECON, P. R.; BRUCKNER, C. H.; ROCHA, A.Qualidade póscolheita de banana 'Prata' tratada por hidrotermia. Ciência e Agrotecnologia, v.32, n.5, p. 1575-1581, set./ out., 2008.

PERES, N.A.R.; KURAMAE, E.E.; DIAS, M.S. de C.; SOUZA, N.L. de. Identification e characterization of Colletotrichum spp. affeting fruit after harvest in Brazil. Journal of Phytopathology, Oxford, v.150, p.128-134, 2002.

TUITE, J. Plant pathological methods: fungi and bacteria. Mineapolis: Burgess, 1969. 239p.

VENTURA, J.A.; HINZ, R.H. Controle das doenças da bananeira. In: ZAMBOLIN, L.; VALE, F.X.R. do; MONTEIRO, A.J.A.; COSTA, H. Controle de doenças de plantas fruteiras. Viçosa, MG: UFV, 2002. p.839-926. 